\title{
CLINICAL FINDINGS IN CREUTZFELDT-JAKOB DISEASE MIMICKING DEMENTIA WITH LEWY BODIES
}

\author{
Luís Fabiano Marin ${ }^{1,2}$, André Carvalho Felício ${ }^{1,2}$, Denis Bernardi Bichuetti, , \\ William Adolfo Celso dos Santos ${ }^{1,2}$, Lia Raquel Rodrigues Borges ${ }^{7}$, \\ Renata Parissi Buainain ${ }^{7}$, Henrique Ballalai Ferraz ${ }^{3}$
}

Creutzfeldt-Jakob disease (CJD) is a transmissible spongiform encephalopathy or prionic disease characterized by accumulation of abnormal prionic protein $\left(\mathrm{PrP}^{\mathrm{Pc}}\right)$ associated to spongiform degeneration of the brain'. Although rare, CJD is the most common prionic disease in humans with an incidence rate around $1 / 1,000,000^{2}$. Historically, it was first described as a dementing illness by Jakob in $1921^{3-5}$. CJD is a rapidly progressive dementia syndrome associated to pyramidal, extrapyramidal and visual signs and symptoms. About $90 \%$ of the affected individuals develop movement disorders throughout the course of CJD and myoclonus is the most common disorder seen in 82 to $100 \%$ of cases $^{6}$. Other movement disorders less frequently seen include: dystonia, choreoathetosis, tremors, and parkinsonian syndrome. The rate of movement disorders increases as CJD progresses and they are less frequently seen in the early stages of disease. Parkinsonism is rarely found as an early manifestation of CJD ${ }^{7}$. CJD can be classified as sporadic, genetic, iatrogenic and variant form ${ }^{2,45,8}$. It is characterized by fast disease progression with a mean survival rate of four months after diagnosis. Two-thirds of patients with CJD die within six months after symptom onset. Some patients at early stages can progress to a state of akinetic mutism ${ }^{1,2}$. Dementia with Lewy bodies (DLB) is a dementia syndrome associated to parkinsonism with little response to L-DOPA, cognitive fluctuations, visual hallucinations, and hypersensitivity to neuroleptics. It has a slower course but life expectancy is 5 to 8 years after symptom onset. DLB is the second most frequent cause of neurodegenerative dementia and its main differential diagnosis are with Alzheimer's disease, Parkinson's disease and some forms of atypical parkinsonism ${ }^{9,10}$. In vivo diagnostic confirmation for both CJD and DLB is a challenge since the gold standard for their diagnosis is pathology examination".

We report a case of CJD that was firstly clinically diag- nosed as DLB, highlighting the occurrence of severe parkinsonian syndrome associated to neuroleptic use.

\section{CASE}

A 65-year-old male patient with no clinical comorbidities or relevant family history developed short-term memory loss, episodes of mental confusion, visual hallucinations and inversion of the sleep-awake rhythm that started three months prior to his first medical evaluation. The patient's symptoms progressively aggravated and he was medicated with a neuropletic drug (risperidone $1 \mathrm{mg}$ at night) for controlling behavioral disorders. Three days after the introduction of risperidone the patient developed bilateral symmetrical rigid-akinetic parkinsonian syndrome showing high severity scores (Hoehn \& Yahr=4, Unified Parkinson's Disease Rating Scale part III=60, Schwab \& England $=20 \%$ ) that made him bedridden and unable to eat independently. He was admitted to the hospital for investigation of his parkinsonian syndrome associated to behavioral-cognitive symptoms and a diagnostic hypothesis of DLB was made. Although risperidone was discontinued and biperiden was given at a dose of up to $16 \mathrm{mg}$ a day, the patient did not show any symptom relief and developed myoclonus in the face and extremities. Serological (HIV, syphilis, hepatitis B and C) and rheumatology tests, and vitamin B12 and folic acid measurements were all normal. Brain magnetic resonance imaging (MRI) showed abnormal signal intensity in putamen and caudate nucleus and in the surface area of cortical gyri bilaterally in FLAIR and diffusion imaging sequences (Fig 1). The electroencephalogram (EEG) revealed generalized short periodic triphasic wave complexes (Fig 2) and 143-3 protein was detected in the cerebrospinal fluid (CSF). Since these findings were all consistent with CJD, the initial diagnosis of DLB was changed.

During his admission the patient progressed with apathy, difficulties with understanding and expression, akinetic mutism and required enteral feeding, tracheostomy and respiratory support.

\section{ACHADOS CLÍNICOS DA DOENÇA DE CREUTZFELDT-JAKOB MIMETIZANDO DEMÊNCIA COM CORPOS DE LEWY \\ 'Equipe de Neurologia do Hospital e Maternidade Santa Helena, São Paulo SP, Brasil; 'Pós-graduando do Departamento de Neurologia da Universidade Federal de São Paulo (UNIFESP), São Paulo SP, Brasil; ${ }^{3}$ Chefe do Setor de Distúrbios do Movimento da Universidade Federal de São Paulo (UNIFESP), São Paulo SP, Brasil.}

Received 13 February 2008, received in final form 19 June 2008. Accepted 10 July 2008.

Dr. Luís Fabiano Marin - Rua Maranhão 192 / 101 - 01240-000 São Paulo SP - Brasil. E-mail: luisfabianom@gmail.com 


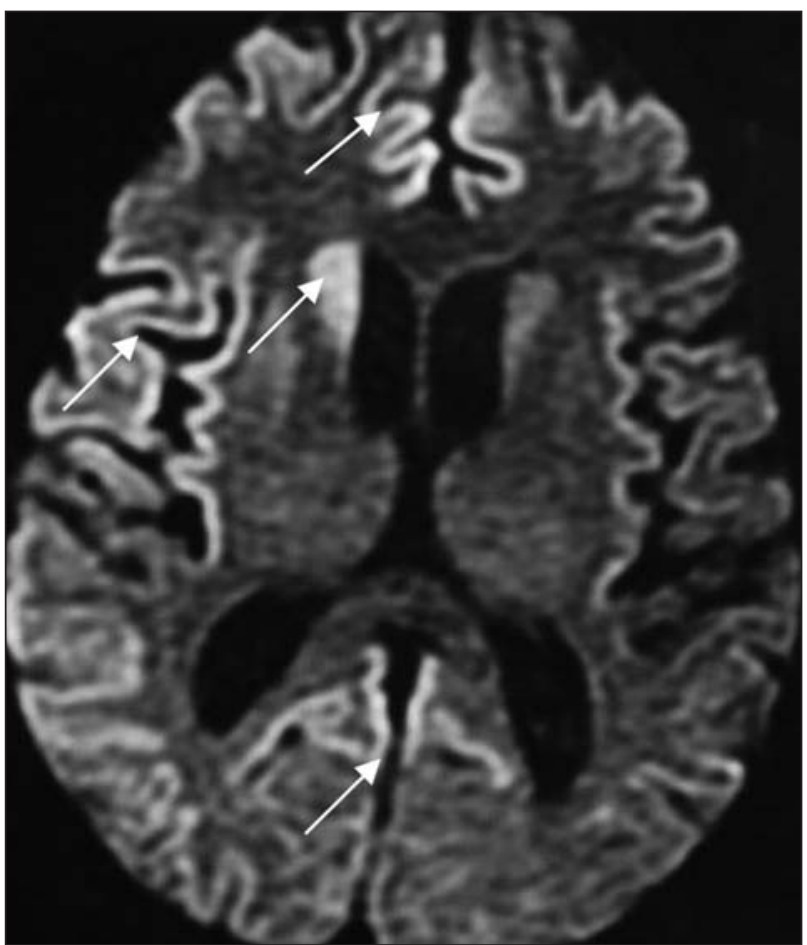

Fig 1. Axial brain MRI showing in the diffusion sequence hypersignal in the right caudate nucleus and frontal, temporal and occipital cortical gyri.

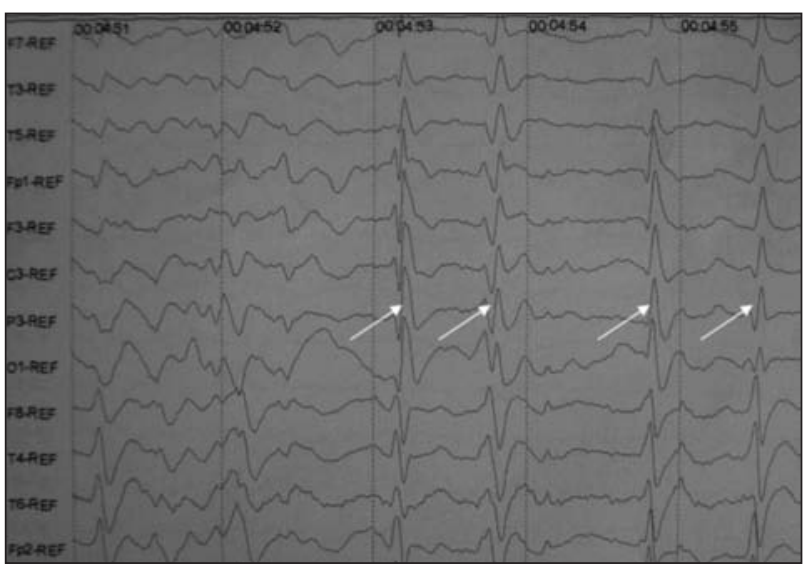

Fig 2. Electroencephalogram showing generalized short periodic triphasic wave complexes (arrow)

The patient died seven months after symptom onset due to respiratory complications.

Informed consent to allow data publication was signed by the patient responsible relative.

\section{DISCUSSION}

The diagnostic hypothesis of CJD should be suggested in any patient aged between 55 and 65 years with history of rapidly progressive dementia syndrome associated to pyramidal, extrapyramidal, cerebellar or visual symptoms ${ }^{1,2}$. Some clinical presentations of CJD can mimic a wide range of typical and atypical parkinsonian syndromes. Lida et al. reported the association of Parkinson's disease and a sporadic form of CJD in a 64-yearold female patient with dementia and progressive parkinsonian symptoms over 4 years. Pathology examination showed findings consistent with both diseases ${ }^{12}$. Kawasaki et al. were the first to report a case of sporadic CJD in a 64-year-old male patient with a 53-month history of progressive dementia syndrome associated with clinical findings of progressive supranuclear palsy and dysautonomia ${ }^{13}$. One more case was reported by Shimamura et al. and two other cases by Josephs et al. showing vertical supranuclear ophthalmoplegia and symmetrical parkinsonism with predominant axial rigidity and disease course between 10 and 29 months ${ }^{14,15}$. Cannard et al. reported a case of a patient with CJD and atypical history of corticobasal degeneration ${ }^{16}$. On the other hand, patients with rapidly progressive dementia manifestations associated to parkinsonian symptoms have been misdiagnosed as CJD but subsequently they were confirmed as DLB cases in the pathology examination ${ }^{17}$.

DLB has several clinical characteristics in common with CJD such as cognitive deficit, and movement and behavioral disorders ${ }^{11,18}$. These clinical features may lead to diagnostic confusion at early stages in both diseases and additional exams may be necessary to provide diagnostic confirmation. DLB is diagnosed according to clinical crite$\mathrm{ria}^{18}$ and supported by occipital hypoperfusion on SPECT; a definite diagnosis can only be established by autopsy?. On the other hand, CJD is supported by cerebrospinal fluid findings (positive 14-3-3 protein on CSF), brain magnetic resonance imaging (hyperintensity of the basal ganglia) ${ }^{19,20}$, but a definite diagnosis can also only be made by autopsy.

Hypersensitivity to neuroleptics leading to or aggravating parkinsonian symptoms is a clinical diagnostic feature of DLB. In the case reported here, the patient had severe manifestations of parkinsonism while taking lowdose risperidone with no relief after its discontinuation. We believe his hypersensitivity was due to preexisting anatomical and functional alterations in the basal nuclei, as shown in Figure 1, caused by CJD. This hypersensitivity to neuroleptics might be a major factor leading to diagnostic confusion between DLB and CJD as Lemstra et al. ${ }^{18}$ pointed out in their study.

In conclusion, there can be diagnostic confusion between DLB and CJD in patients with rapidly progressive dementia syndrome associated to extrapyramidal symptoms, behavioral disorders, and hypersensitivity to neuroleptics. The detection of 14-3-3 protein in CSF, abnormal signal intensity in the basal nuclei in brain MRI and short disease course are findings suggestive of $C \mathrm{D}^{17,19,21,22}$. The finding 
of a periodic pattern in EEG, although regarded highly sensitive to CJD, can also be seen in patients with DLB ${ }^{23,24}$ and should not be used as a single tool for diagnosis.

ACKNOWLEDGMENT - We thank the Epidemiological Surveillance Department for the measurements of 14-3-3 protein in CSF.

\section{REFERENCES}

1. Knignht RSG, Will RG. Prion diseases. J Neurol Neurrossurg Psychiatry 2004;75:36-42.

2. Glatzel M, Stoeck K, Seeger H, Luhrs T, Aguzzi A. Human prion diseases. Arch Neurol 2005;62:545-552.

3. DeArmond SJ, Prusiner SB. Etiology and pathogenesis of prion diseases. Am J Pathol 1995;146:785-811.

4. Richardson EP, Masters CL. The nosology of Creutzfeldt-Jakob disease and conditions related to the accumulation of $\operatorname{PrP}^{\mathrm{CID}}$ in the nervous system. Brain Patlhol 1995;5:33-41.

5. Gambetti P, Parchi P, Petersen RB, et al. Fatal familial insomnia and familial Creutzfeldt-Jakob disease: clinical, pathological and molecular features. Brain Pathol 1995;5:43-51.

6. Will RG, Matthews WB. A retrospective study of Creutzfeldt-Jakob disease in England and Wales 1970-79: 1. Clinical features. J Neurol Neurosurg Psychiatry 1984;47:134-140.

7. Maltête D, Guyant-Marechal L, Mihout B, Hannequin D. Movement disorders and Creutzfeldt-Jakob disease: a review. Mov Disord 2006;12:65-71.

8. Zeidler M, Stewart GE, Barraclough CR, et al. New variant CreutzfeldtJakob disease: neurological features and diagnostic tests. Lancet 1997;350:903-907.

9. McKeith I, Mintzer J, Aarsland D, et al. Dementia with Lewy bodies. Lancet Neurol 2004;3:19-28.

10. Brito-Marques PR, Mello RV, Montenegro L. Nightmares without atonia as an early symptom of diffuse Lewy bodies disease. Arq Neuropsiquiatr 2003;61:936-941.

11. Kraemer C, Lang K, Weckesser M, Evers S. Creutzfeldt-Jacob disease misdiagnosed as dementia with Lewy bodies. J Neurol 2005;252:861-862.
12. Iida T, Doh-Ura K, Kawashima T, Abe H, Iwaki T. An atypical case of sporadic Creutzfeldt-Jakob disease with Parkinson's disease. Neuropathology 2001;21:294-297.

13. Kawasaki K, Wakabayashi K, Kawakami A, et al. Thalamic form of Creutzfeldt-Jakob disease or fatal insomnia? Report of sporadic case with normal prion protein genotype Acta Neuropathol 1997;93:317-322.

14. Shimamura M, Uyama E, Hirano T, et al. A unique case of sporadic Creutzfeldt-Jakob disease presenting as progressive supranuclear palsy. Intern Med 2003;42:195-198.

15. Josephs KA, Tsuboi Y, Dickson DW. Creutzfeldt-Jakob disease presenting as progressive supranuclear palsy. Eur J Neurol 2004;11:343-346.

16. Cannard KR, Galves-Jimenez N, Watts RL. Creutzfeldt-Jakob disease presenting and evolving as rapidly progressive corticobasal degeneration. Neurology 1998;50(Suppl. 4): A95-A96.

17. Tschampa H J, Neumann M, Zerr I, et al. Patients with Alzheimer's disease and dementia with Lewy bodies mistaken for Creutzfeldt-Jakob disease. J Neurol Neurosurg Psychiatry 2001;71:33-39.

18. Lemstra AW, Schoenmaker N, Rozemuller-Kwakkel AJ, van Gool WA. The association of neuroleptic sensitivity in Lewy body disease with a false positive clinical diagnosis of Creutzfeldt-Jakob disease. Int J Geriatr Psychiatry 2006;21:1031-1035.

19. Meissner B, Köhler K, Körtner K, et al. Sporadic Creutzfeldt-Jakob disease: magnetic resonance imaging and clinical findings. Neurology 2004;63:450-456.

20. Pereira E. Diffusion-weighted sequence on MRI for the diagnosis of Creutzfeldt-Jakob disease. Arq Neuropsiquiatr 2002;60:906-908.

21. Nitrini R, Areza-Fegyveres R, Martins VR, et al. Asymmetric cortical high signal on diffusion weighted-MRI in a case of Creutzfeldt-Jakob disease. Arq Neuropsiquiatr 2005;63:519-522.

22. Green A, Sanchez-Juan P, Ladogana A, et al. CSF analysis in patients with sporadic CJD and other transmissible spongiform encephalopathies. Eur J Neurol 2007;14:121-124.

23. Doran M, Larner A. J. EEG findings in dementia with Lewy bodies causing diagnostic confusion with sporadic Creutzfeldt-Jakob disease. Eur J Neurol 2004;11:838-841.

24. McKeith IG, Galasko D, Kosaka K, et al. Consensus guidelines for the clinical and pathologic diagnosis of dementia with Lewy bodies (DLB): report of the consortium on DLB international workshop. Neurology 1996;47:1113-1124 